\title{
Design of Simulation Model for Novel Solar Thermal Storage Tank
}

\author{
Muthalagappan Narayanan*, Gerhard Mengedoht, Walter Commerell
}

Hochschule UIm, Prittwitzstraße 10, 89075 UIm, Germany; *narayanan@hs-ulm.de

SNE 27(3), 2017, 131 - 136, DOI: 10.11128/sne.27.tn.10382

Received: June 10, 2017 (Selected ASIM GMMS/STS 2017

Postconf. Publ.), Accepted: July 20, 2017

SNE - Simulation Notes Europe, ARGESIM Publisher Vienna,

ISSN Print 2305-9974, Online 2306-0271, www.sne-journal.org

Abstract. Due to the fluctuated availability of solar energy, the solar thermal energy systems are designed by simulation as to have a system which will satisfy the loads as expected. The thermal storage tanks are existing since a long time but however there is still research going on and new novel tanks are introduced. One such tank is the Hybrid Quattro thermal storage tank from Sailer $\mathrm{GmbH}$. This storage tank have new patented lances, which helps in stratification of the tank and thus higher efficiency of the energy storage without mixing of the layers in the tank. For designing of an energy system with this storage tank, a simulation model of this tank is required. Thus a test of this storage tank is done and the parameters were identified which later was used to build up a component model for storage in TRNSYS software using the type 340 storage tank model. This paper explains the process of identifying parameters from a real storage tank to a simulation model which can be used further for simulating a storage tank which would also make possible for the storage tank to be optimized for a development in the efficiency for the system performance.

\section{Introduction}

Currently Hochschule Ulm along with Sailer GmbH and other partners is working in the project Intelligent Home Energy Management (iHEM) funded by BMWi. The main objective of this project is to integrate thermal and electrical components with more energy sources at high efficient operation in a household for high self utilization.
For an intelligent control of such a system, the load and production energy are forecasted and an optimum predictive operation strategy is found out so that the system is not only efficiently optimized and self utilization prioritized with maximum possible renewable energy ratio but also economically and strategically viable. The subjective goal of the project is to have an integrated home energy system communicating with all the components through a superior management component.

Hochschule Ulm is involved in simulating different buildings with TRNSYS and finding out the design and sizing of different thermal and electrical systems like fuel cell CHP, gas boiler, solar thermal collectors, PV, thermal storage tank, battery such that the demand of the buildings are met. Also one final step of the project is to build a demonstrator with all these system components and present the intelligent control and integrated working of these. Also Hochschule Ulm is involved in design and monitoring of the demonstrator. More information about the project can be found at [1].

In project iHEM (Intelligent Home Energy Management), for system design the novel solar thermal storage tank from Sailer GmbH needs to be sized.

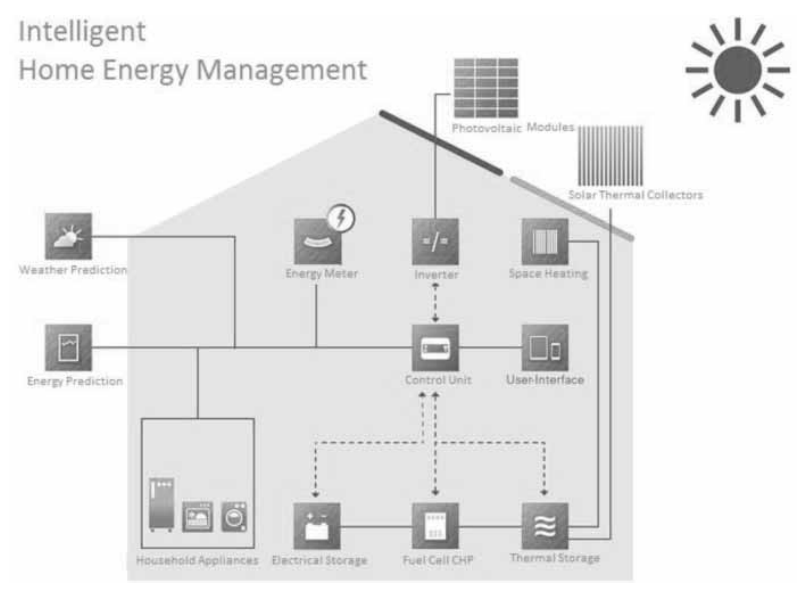

Figure 1. Overview of iHEM. [1] 
The storage tanks include patented lances which are efficient enough to form layers in the tank such that the temperature gradients inside the tank are maintained and hence avoiding mixing which results in efficient storage of heat. The first sub-motive of the project is to size the storage tank for design of the entire energy system.

Due to the fact that this is a complicated system, simulation of the system is required for designing the size of each component. For such simulations with high dynamic possibilities is the software TRNSYS (Transient System Simulation Tool) [2] famous. For the degree of freedom and its module plug and play concept, they are so flexible and customly designable. Each of the component in the system is a separate block in which the parameters can be defined. Also each of the output and input of the components can be interconnected so that they can communicate with each other. In TRNSYS there are lots of pre-developed models available which can be connected together and integrated as a system, just like in Matlab/Simulink. Furthermore, new component models can be coded and created. To design the system, the simulations have to be carried out with a storage tank model which would be able to simulate the Hybrid Quattro storage tank. Type 340 component model, pre-developed complicated tank component would be used here to model the tank. Below in section 1.1 and 1.2 the unique storage tank and the TRNSYS Type 340 model features are explained.

\subsection{Hybrid Quattro storage tank}

Usually a hot water storage tank is charged and discharged using fixed direct ports. So regardless of the temperature of the hot water produced by solar thermal collectors or the temperature in the layer where the port is, the hot water is injected in this layer and this in return mixes the tank layers and the temperature gradient inbetween the top and bottom is less. This causes the temperature of the discharge low. One more aspect is that the discharge return temperature depends on the application it is being used for and if return temperature is hotter and still useful this is also wasted by mixing the layers. For example when a solar collector produces $70^{\circ} \mathrm{C}$ hot water which is being fed into the top of the tank and after some time when the sun radiations are reduced the temperature reduces to say $50^{\circ} \mathrm{C}$ then this also is fed into the same layer in tank which mixes the layer and reduces the efficiency. For this the heat exchangers were built inside the tank.
The same applies for the discharging, when warm water is being used for space heating in buildings, the return temperature really depends on the demand of heat enery in buildings and the flow rate of the radiators. Also one more factor is that the discharging outlet temperature also depends on the temperature taken out from the tank for discharge to deliver energy.

Even though heat exchangers were better than direct charging and discharging, they were still not perfect and energy efficient as the heat exchangers cover only some layers and in these layers there may be a temperature gradient which might be destroyed. Thus came into existence, the stratification lances. These lances are mere plastic pipes which have openings at several layers inside the tank. The first kind of lances was developed by Solvis $\mathrm{GmbH}$. These lances are normal pipes which have openings at perpendicular angles in a right angle direction. The Solvis lances are shown in Figure 2 to the left. Also in the same figure you can see the Sailer lances in the right.

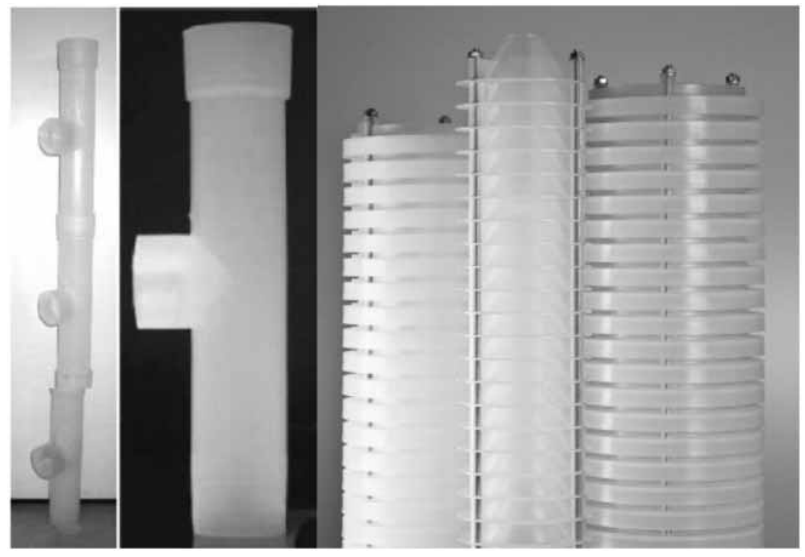

Figure 2. Stratification lances from Solvis $\mathrm{GmbH}$ (on the left) [3], and Sailer $\mathrm{GmbH}$ (on the right, where the middle lance is used for solar energy i.e. natural convection input). [4]

Definitely Solvis lances were a breakthrough but since it was right angled and directed to one point in a cylindrical layer, they did have some mixing. Hence were the newly developed Sailer lances, these had a 360 degree fool proof lances which had to take a convection fool proof design which made them even efficient. In a whole system point of view these tanks improve the efficient use of the energy system and higher useful energy ratio (useful energy/energy input). 
This combistore is claimed to be $60 \%$ more efficient than direct charging/discharging combistores by Sailer $\mathrm{GmbH}$ [5]. A comparison of the two stratification lances were made by Andersen et al. through CFD simulations, forced flow and the thermosyphon flow tests [6].

More efficient than the normal solar energy heat exchangers are the heat exchangers with stratification lances concept used here by the hybrid quattro tank. Since the heat exchangers if installed alone, the stratification is disturbed and when only lances are used glycol solution cannot be used in the tank.

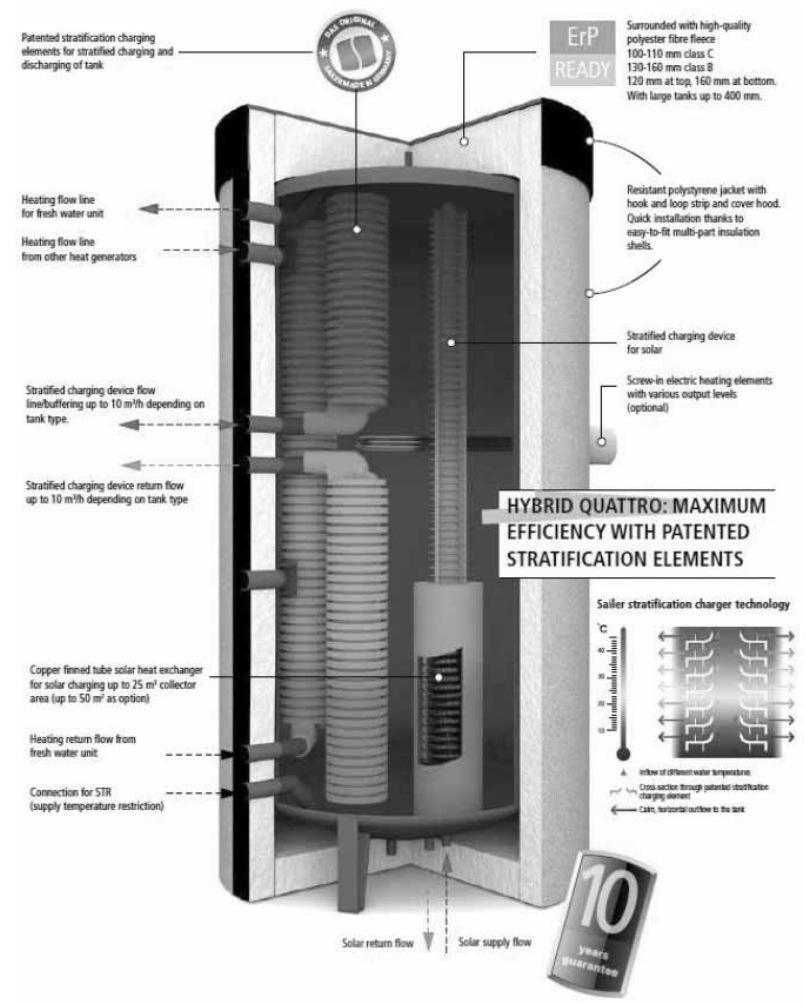

Figure 3. Sectional view of the Hybrid Quattro tank with the stratification lances. [5]

Until now tanks used an external heat exchanger which transfers heat from glycol loop to the water loop and the hot water is fed into the tank with lances. But here they use the natural convection of the water and the density in the heat exchange-lance combo. The heat exchanger inside the tank brings heat and transfers it to the nearby water and due the fact that this water in the enclosure is high of density it moves via the lance to the respective layer and the cold water flows in the enclosure of the heat exchanger from the bottom to absorb the heat from the glycol-water solution from the solar collectors.

\subsection{TRNSYS Type 340}

The TRNSYS Type 340 is a storage model for a multiport tank component. This was developed by ITW, UniStuttgart and is a non standard model available for purchase and can be easily integrated into the TRNSYS Library. The storage tank has a provision for up to 10 lances and 4 heat exchangers with up to 200 nodes (same temperature layers) and an electrical auxiliary heater. In Figure 4, it can be seen that the model is very flexible and is mathematically coded.

The number of nodes can be input and they are equally divided from the input height and volume. The tank heat loss can be either given as a value same in all directions or can be varied between different parts of the store. The heat exchanger and the lances can be combined to have a heat exchanger which will send the hot fluid via lances to the stratified layer. Also all the lance's input height, output height, flow direction and also if it there is a lance (stratified or direct ports) can be given. Also the heat transfer capacity rate has to be put in. There is also the facility to have one internal electrical auxiliary heater.

There are also some limitations to the model. It cannot have a lance with only one inlet/outlet port. It is assumed in the model that the mass flow in one lance, i.e. in the outlet and inlet is meant to be a constant value.

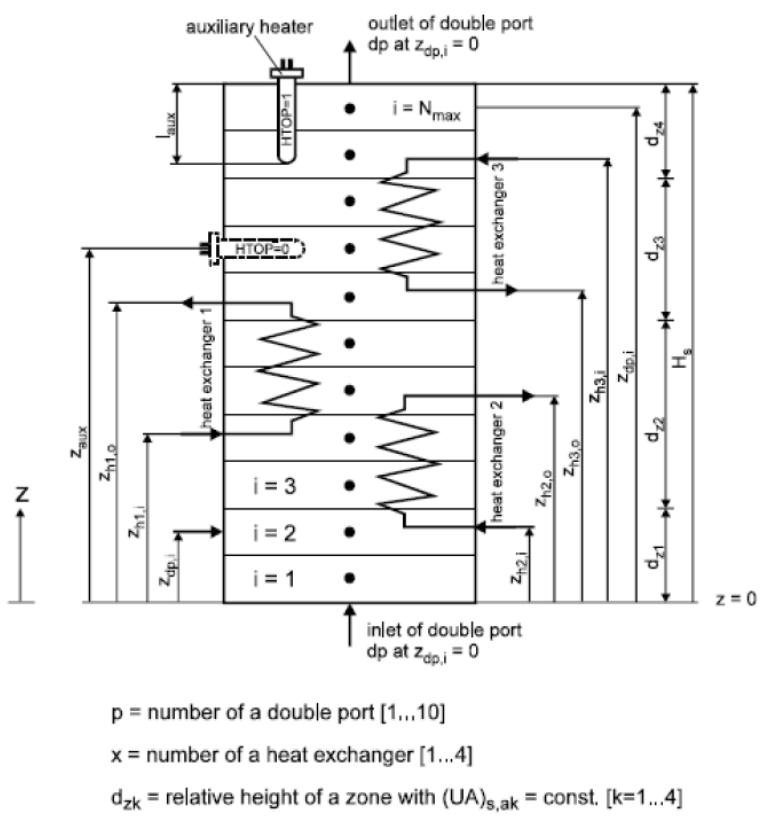

Figure 4. Schematic of the multiport store model as it is in TRNSYS type 340 component model. [7] 
So always the lances should be connected to a closed loop in which the mass flow of the inlet and outlet of the lances should be same. Each of the heat exchangers is substituted for a lance and if one uses the maximum available 4 heat exchangers then there are only 6 lances available for the connection. This is because whenever a heat exchanger is connected, there arises sometimes a need to have a lance connected to this heat exchanger. Thus mathematically either of the heat exchanger or the connected lance could only be used.

\section{Methodology}

As there are different types of hot water storage tanks and there are diferrences in how they perform a common test method in which parameters can be identified in order to compare them is required. Also for simulation of these tanks and designing a whole energy system these parameters are required. As a development of IEA Task 16, a European Standard EN 12977-4 was formed for performance test analysis of solar combistores.

According to EN 12977-4, as specified in [8], there are different types of solar thermal storage tanks and briefly combistores can be classified into 5 types with direct/indirect charge and discharge modes. In this case for Hybrid Quattro tank, the charge ports are both direct and indirect while the discharge ports are only direct discharge. There are fresh water station heat exchangers externally which also have to be taken into account. Depending on the type of the combistore a different test methodology is specified and the tests are done in two types-entire store and a certain volume (auxiliary part) to determine heat loss capacity rate and thermal stratification loss (effective vertical thermal conductivity) respectively. Other than this the whole procedure gives many additional useful parameters like effective volume, heat transfer capacity rate, stratified charging capacity, etc. And the end of post processing of the test results with parameter fitting, the parameters for the respective tank are identified. The other physical parameters like inlet and outlet port heights, lances length, tank volume, height and sensors, heat exchanger and lances performances etc. can be obtained from the manufacturer. This standard testing can be done in any authorized test center that has this combistore test bed.

For this case, a $2 \mathrm{~m}^{3}$ Hybrid Quattro Sailer GmbH's Combistore Tank was tested by ITW, Uni-Stuttgart and the performance parameters were identified. The challenge then is to design a model to simulate such a complex storage tank.
Not only in this project is it looked to simulate the storage tank but also to find optimal tank parameters for different energy systems and buildings. The optimization of tank includes varying the height of the inlet and outlet ports, volume of the tank, electrical heater placement, electrical heater power, insulation, etc. Hence also the store size has to be varied and hence the parameters such as heat loss rate would vary and influence the simulation results. As known, the heat loss rate varies with respect to the insulation thickness, insulation material and surface area of the storage tank.

Therefore basically the insulation can assumed to be varied in such a way that the surface area alone varies the heat loss rate, so that the magnification of the combistore for simulations is viable. The effective vertical thermal conductivity increases as the tank size decreases but as they are small in context they are neglected. Overall when there is a need to increase the size of the combistore, the height and the volume is modified with the heat loss modified and all the other paramters are withheld the same.

\section{Simulation Realization}

Now with the test results done and the parameters identified, the task following is to bring in these to the simulation model. As already explained TRNSYS software is used and type 340, a multiport storage model is used. Even though this is one of the best component model for storage tanks, it has some limitations. In Figure 3, it can be seen that there are two ports in the middle of the tank which is connected to the stratification lances. The main idea of these lances are that these two lances can be used in for two different operations together as shown in Figure 5.

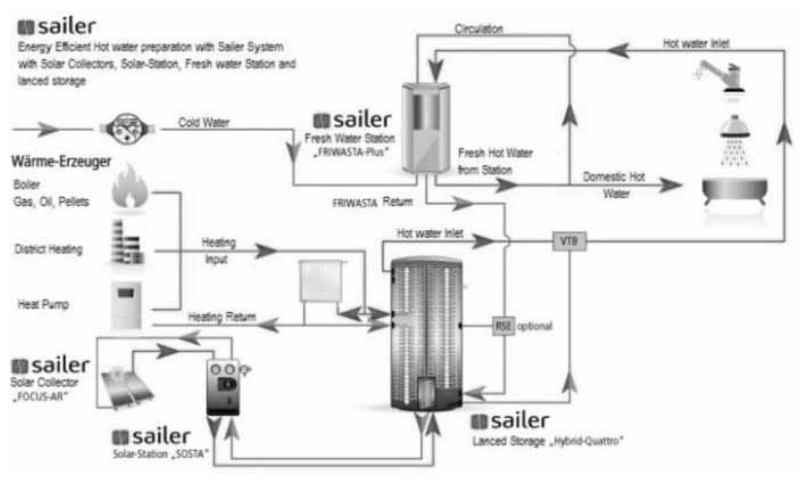

Figure 5. Schematic of the Sailer hybrid quattro tank as it is functioning in the real system. [9] 
In most of combistores there is an auxiliary boiler and it is also connected to radiators for space heating. The principle of the radiators operation is that it takes out warm water from the middle of the tank i.e. from the top of a lance and returns back to the bottom of the same lance which inserts the water in the relevant temperature. Vice versa, for the auxiliary boiler, in this project a gas boiler, the warm water is taken from the middle of the tank i.e. from the bottom of another lance and is heated. The hot water from the gas boiler is fed back to the tank via the top of the same lance so that the hot water reaches the layer with relevant temperature.

One more advantage of this configuration is that during the winter days, without using the tank for buffer, the gas boiler can directly power the space heating radiators. One necessary equipment for this setup is a two way pump which is missing in TRNSYS library. Most importantly, type 340 is modelled or coded in such a way that always the input and output of each lance is two different ports and only with the direction of the lance, the component model defines if it is charging in energy or taking out. Also it is designed that the mass flow in between these input and output port is constant and hence if one of the port is not connected, it gives an error. Therefore it is practically possible to use a stratification lance with just one port but mathematically, not just in TRNSYS for type 340 but also in any other platform, this is not viable. Therefore this configuration setup has to be varied in simulation which differs from reality but the principle of the lances is still feasible. The difference in the simulation model to reality can be seen in Figure 6. One more similar change is that the lances are connecting the fresh water station.

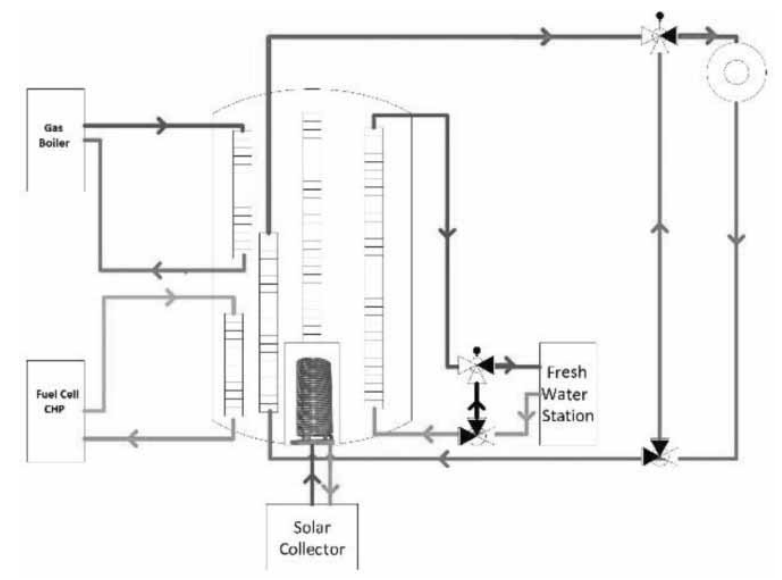

Figure 6. Overview of the simulation setup for the tank model.
The real operation is that the fresh water station takes hot water from the top of the tank via a direct port and exchanges the heat to the fresh cold water and the return warm water is fed to the lances which in turn delivers to the respective layer in the tank. Instead of this setup in the tank the inlet and outlet to the fresh water station is connected to the single lance.

\section{Results and Conclusion}

The primary aim of the paper is to build a component model for the Hybrid Quattro Storage Tank from Sailer $\mathrm{GmbH}$. The process for building a simulation model for a storage tank is presented in this paper. Since the storage tank is a novel tank with the stratification lances, the parameter identification and simulation turns out to be challenging. With certain conceptual changes between the real system and the simulation model, the simulation model is executed.

The advantage of the simulation model is that the size of the tank can be varied and can be looked into for various cases. The simulation model also is helpful to vary the port inlet and outlet heights according to the system so that the total system efficiency is high. In a following task as part of the iHEM project, the developed simulation model is used to build an energy system model consisting of solar thermal collectors, gas boiler, fuel cell CHP, building heat load and domestic hot water load. Also PV, battery and inverter are modelled so that the electrical auxiliary heater in the hot water storage tank is supplied with the excess electrical energy.

Finally the motive of the project is to compare the different buildings in Germany and the strategy for such a home energy system and the sizing. For example, for a sun house standard, the solar fraction needs to be minimum 50\% while for a KfW55 house the primary energy used in the house should be less than $55 \mathrm{kWh} / \mathrm{m}^{2}$. Thus the collector area, PV size, storage size, etc. are different for different buildings and the approach for each building types's system optimization is different. Not only that but also the tank also needs to be optimized for each of the building type according to their energy requirements and system size. 
The fact that Sailer GmbH has the option to build custom-made different tanks according to the requirements of each customer is an advantage. So the end result might be to find a tank design and a sizing factor for each of the building types. Also there is a real running system of all these components, and their management strategies and control would be realized in a demonstrator system at the end of the project.

\section{Acknowledgement}

The work described in this paper is a part of the project Intelligentes Heimenergiemanagement (iHEM) and the Research Initiative Energiespeicher funded by the Bundesministerium für Wirtschaft und Energie under the Project Number -03ET1205A.

\section{References}

[1] Photovoltaik Augsburg: Solarthermie, Photovoltaikanlage - iHEM. [Online]. Available: http://www.ihem.eu/. [Accessed: 13-Jan-2017].

[2] Transient System Simulation Tool - TRNSYS. Madison USA.: Thermal Energy System Specialists, LLC., 2014.

[3] Shah LJ, Andersen E, Furbo S. Theoretical and experimental investigations of inlet stratifiers for solar storage tanks. Appl. Therm. Eng., vol. 25, no. 14-15, pp. 2086 2099, Oct. 2005.
[4] Sailer GmbH Ehingen - Patented stratification charger technology. [Online]. Available: http://www.sailergmbh.de/en/products/sailerstratifiedstorage-tanks/patented-stratificationcharger- technology.html. [Accessed: 13-Jan- 2017].

[5] Sailer GmbH Ehingen - Schichtenspeicher. [Online]. Available: http://www.sailergmbh.de/en/products/schichtenspeicher / schichtenspeicher.html. [Accessed: 13-Jan-2017].

[6] Andersen E, Furbo S, Hampel M, Heidemann W, Müller-Steinhagen $\mathrm{H}$. Investigations on stratification devices for hot water heat stores. Int. J. Energy Res., vol. 32, no. 3, pp. 255-263, Mar. 2008.

[7] Drück H. Mutliport Store Model for TRNSYS -Type 340. Institut für Thermodynamik und Wärmetecknik (ITW), Universität Stuttgart, Mar-2006.

[8] FprEN 12977-3:2016, Thermal solar systems and components - Custom built systems - Part 4: Performance test methods for solar combistores.

[9] Sailer GmbH Ehingen - Diagram: Hybrid Quattro in heating circuit. [Online]. Available: http://www.sailergmbh.de/en/products/sailerstratifiedstorage-tanks/diagram-hybrid-quattroin-heatingcircuit.html. [Accessed: 13-Jan-2017]. 